\title{
Expression of the chemokine CCL28 in pleomorphic adenoma and adenolymphoma of the human salivary glands
}

\author{
GUO-XIN LIU ${ }^{1 *}$, JING LAN $^{1 *}$, YING SUN $^{2}$, YI-JUN HU ${ }^{1}$ and GUANG-SHUI JIANG ${ }^{1}$ \\ ${ }^{1}$ Shandong Provincial Key Laboratory of Oral Biomedicine, School of Stomatology, Shandong University, \\ Jinan 250012; ${ }^{2}$ Department of Stomatology, Xiqing Hospital of Tianjin, Tianjin 300380, P.R. China
}

Received January 16, 2012; Accepted February 27, 2012

DOI: $10.3892 /$ etm.2012.544

\begin{abstract}
Recent studies have proposed that the chemokine CCL28 is constitutively expressed by epithelial cells in salivary glands and play an important role in lymphocyte trafficking in oral immunity. To date, there is little information on the expression pattern of CCL28 in salivary gland tumors. The purpose of this study was to determine the expression of CCL28 in pleomorphic adenoma and adenolymphoma and to evaluate its potential function in regulating oral carcinogenesis. Immunohistochemical reactivity revealed CCL28 protein expression in the cytoplasm of acinar epithelial cells, both in tumorous tissues and normal adjacent tissues. The level of CCL28 mRNA was markedly reduced in 70\% (28/40) of pleomorphic adenomas, and in $81 \%$ (26/32) of adenolymphomas, compared to the normal adjacent tissue. CCL28 protein expression was significantly lower in pleomorphic adenomas $(\mathrm{P}=0.0027, \mathrm{n}=40)$ and in adenolymphomas $(\mathrm{P}=0.0003, \mathrm{n}=32)$ compared to their normal adjacent tissues. Additionally, the CCL28 protein levels in saliva in the aforementioned patients were lower than those in healthy volunteers. Our study indicated that the reduced expression of CCL28 could possibly be a strategy by recruiting fewer antitumor immunocompetent cells to salivary glands. The expression and secretion of CCL28 may be associated with the pathogenesis of pleomorphic adenoma and adenolymphoma.
\end{abstract}

\section{Introduction}

Pleomorphic adenoma is one of the most common salivary gland tumors, which mainly occurs in the parotid gland and

Correspondence to: Professor Guang-Shui Jiang, Shandong Provincial Key Laboratory of Oral Biomedicine, School of Stomatology, Shandong University, 44 Wenhua Xi Road, Jinan 250012, P.R. China

E-mail: gjiang@sdu.edu.cn

\section{*Contributed equally}

Key words: chemokine, CCL28, pleomorphic adenoma, adenolymphoma, salivary gland the submandibular gland. Although most of the pleomorphic adenomas are benign tumors, they have a tendency to be transformed into malignant tumors in their natural course (1). Adenolymphoma, also known as Warthin's tumor, is the second most common benign tumor of the salivary glands. The development of adenolymphoma is related to the epithelial cells of the heterotopic salivary gland in the intraparotid lymph nodes (2). Elucidation of the factors related to the pathogenesis of pleomorphic adenoma and adenolymphoma may be favorable to the understanding and management of such human illnesses.

Chemokines are a superfamily of low-molecular-weight chemotactic cytokines, which are best known for inducing leukocyte trafficking during inflammation and were recently found to be involved in the migration of tumor cells (3). The role played by chemokines in tumor development is complex as some chemokines favor tumor progression, while others may facilitate the generation of effective antitumor immunity (4).

The chemokine CCL28 (also named mucosa-associated epithelial chemokine, MEC) belongs to the $\mathrm{C}-\mathrm{C}$ chemokine subfamily and is a CCR10/CCR3 ligand commonly produced by epithelial cells in different mucosal tissues such as the mammary gland, salivary gland, intestine and colon (5-8). CCL28 is consititutively expressed by these mucosal epithelial cells and is considered to chemoattract subpopulations of CD4/CD8 T cells in mucosal immunity. For example, CCL28 is markedly increased in inflamed colon epithelium, and its production is also upregulated by proinflammatory stimuli, suggesting the role of CCL28 in counter-regulating colonic inflammation (9). A more recent study on CCL28 expression in human colon and rectum cancers revealed that there was a notable suppression of CCL28 protein in colon tumors while no significant difference was noted between rectum tumors and adjacent normal tissue (8). The authors claimed to do further investigations to clarify the role of CCL28 in colorectal carcinogenesis, nevertheless this study presented information concerning the regulation of CCL28 expression in cancer.

In salivary glands, CCL28 has been shown to have dual functions in mucosal immunity as a chemokine attracting $\mathrm{T}$ cells and also as a potent antimicrobial factor against pathogens (7). However, little is known regarding the role of CCL28 in the pathogenesis of salivary gland tumors. Here, we investigated the expression of CCL28 in pleomorphic adenoma and adenolymphoma from a relatively large number 
of corresponding patient samples and to assess its potential impact on oral carcinogenesis.

\section{Materials and methods}

Patients and tissue preparation. The protocol for this paper was evaluated and approved by the Ethics Committee of the Stomatology Hospital of Shandong University. All patients and volunteers signed an informed consent form regarding the collection of the samples. The parotid gland tissues were obtained from patients with pleomorphic adenoma (40 patients) or adenolymphoma (32 patients) during surgical resection. The diagnoses were carried out at the Department of Oral and Maxillofacial Surgery, Qilu Hospital of Shandong University between 2008 and 2009. All tumorous tissues and normal adjacent salivary tissues (approximately $1 \mathrm{~cm}$ away from the tumor) were removed from each patient, and all tissues were frozen immediately at $-70^{\circ} \mathrm{C}$ until their use.

Saliva collection and preparation. Whole saliva samples were collected from 45 healthy volunteers, 40 pleomorphic adenoma patients and 32 adenolymphoma patients without any stimulation to preserve their natural composition. In order to minimize temporal fluctuations, all samples were collected between 09:00 and 10:00 $\mathrm{h}$ at least $60 \mathrm{~min}$ after food or liquid ingestion. Whole unstimulated saliva samples in sterilized centrifuge tubes were centrifuged at $10,000 \mathrm{x}$ g for $20 \mathrm{~min}$ at $4^{\circ} \mathrm{C}$. The supernatants were collected and stored in small aliquot tubes at $-70^{\circ} \mathrm{C}$ until required for use.

Immunohistochemistry. The tissue specimens were fixed in $4 \%$ paraformaldehyde, dehydrated conventionally and embedded in paraffin. Sections $(5 \mu \mathrm{m})$ were deparaffinized, rehydrated, and treated with $0.3 \% \mathrm{H}_{2} \mathrm{O}_{2}$ in PBS for 10 min at room temperature to block endogenous peroxidase activity, and block non-specific binding sites with rabbit serum in PBS for $20 \mathrm{~min}$. The sections were incubated overnight at $4^{\circ} \mathrm{C}$ with the CC chemokine (CCL28) chicken anti-human polyclonal antibody (Abcam, Cambridge, MA; Lifespan Biosciences, Seattle, WA) diluted 1:100, then incubated with biotin-labeled rabbit anti-chicken IgY (1:100 dilution; Abcam; Lifespan Biosciences) for 30 min. After incubation with HRP, the sections were stained with 3,3-diaminobenzidine. Finally, all the sections were counterstained with hematoxylin.

Real-time PCR. Total-RNA was extracted from $50 \mathrm{mg}$ of freshly isolated tissues using an acid guanidinium-phenol-chloroform method following the manufacturer's instructions (TRIzol reagent; Gibco-BRL; Life Technologies, Grand Island, NY). Reverse transcription was performed following RevertAid ${ }^{\mathrm{TM}}$ First Strand cDNA Synthesis kit (MBI Fermentas, Burlington, ON, Canada). Real-time PCR was carried out using an ABI PRISM 7000 Sequence Detection System (PE Applied Biosystems, Foster City, CA) in conjunction with the SYBRGreen PCR kit (Takara, Kyoto, Japan). PCR primers for CCL28 were as follows: 5'-CAG AGA GGA CTC GCC ATC GT-3' (sense) and 5'-TGT GAA ACC TCC GTG CAA CA-3' (antisense), yielding a 101-bp product. The housekeeping $\beta$-actin gene was used as an internal control for the examination of human gene expression, and the primer sequences were 5'-GAC

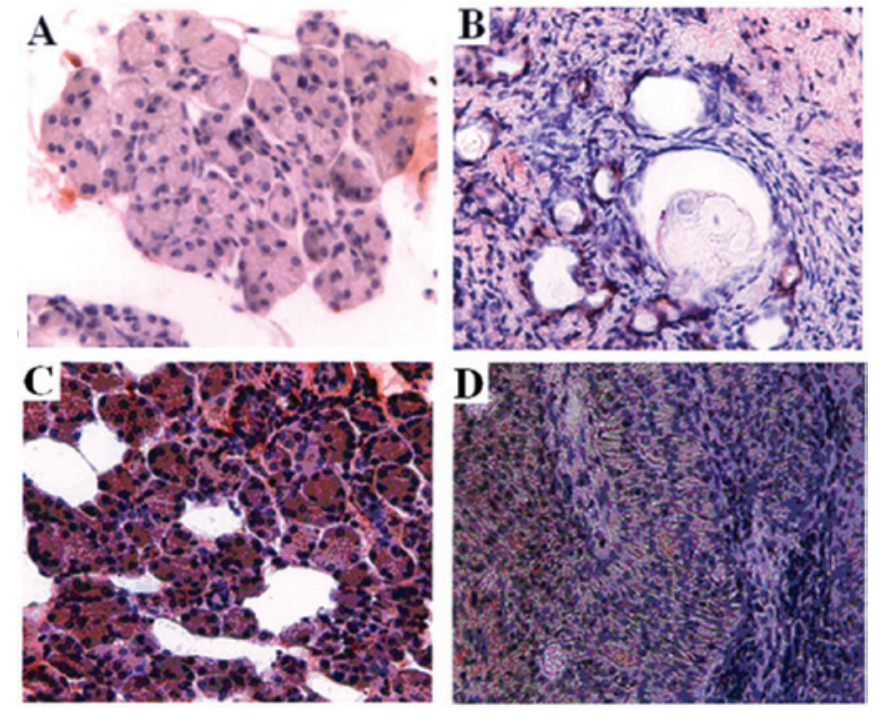

Figure 1. Immunolocalization of CCL28 in salivary gland tumors. (A and B) Sections from normal adjacent salivary gland tissue and pleomorphic adenoma tissue, respectively. (C and D) Sections from normal adjacent salivary gland tissue and adenolymphoma tissue, respectively.

TAC CTC ATG AAG ATC CTC ACC-3' (sense) and 5'-TCT CCT TAA TGT CAC GCA CGA TT-3' (antisense), yielding a 85 -bp product. Fold changes in CCL28 mRNA expression were determined as $2^{-\Delta \Delta \mathrm{Ct}}$, where $-\Delta \Delta \mathrm{Ct}=-\left[\left(\mathrm{Ct}_{\mathrm{CCL} 28 u n k n o w n}{ }^{-}\right.\right.$ $\left.\left.\mathrm{Ct}_{\beta \text {-actin unknown }}\right)-\left(\mathrm{Ct}_{\mathrm{CCL} 28 \text { control }}-\mathrm{Ct}_{\beta \text {-actin control }}\right)\right]$. The results are expressed as means $\pm \mathrm{SD}$.

Protein preparation. Frozen tumorous tissues and normal adjacent tissues were thawed and homogenized in ice-cold RIPA lysis buffer ( $\mathrm{pH} 7.4,50 \mathrm{mM}$ Tris- $\mathrm{HCl}, 150 \mathrm{mM} \mathrm{NaCl}$, $1 \%$ Nonidet P-40, $0.5 \%$ sodium deoxycholate, $0.1 \%$ sodium dodecyl sulphate (SDS), $1 \mathrm{mM}$ sodium orthovanadate, $1 \mu \mathrm{g} / \mathrm{ml}$ leupeptin, $1 \mathrm{mM}$ EDTA) and $100 \mu \mathrm{g} / \mathrm{ml}$ phenylmethylsulphonyl fluoride (PMSF). The lysates were placed on ice for $30 \mathrm{~min}$ and then centrifuged at $13,000 \mathrm{x}$ g for $10 \mathrm{~min}$, and the supernatant fluids were stored at $-20^{\circ} \mathrm{C}$ until required for use. The protein content of the supernatant fluid was determined for each sample using the Bradford protein assay.

ELISA. CCL28 concentration was evaluated in tissues and saliva using an established commercial enzyme-linked immunosorbent (ELISA) kit (R\&D Systems Europe, UK) and following the procedures suggested by the manufacturer. The saliva CCL28 protein concentrations from patients and control subjects were expressed as nanograms per milliliter $(\mathrm{ng} / \mathrm{ml})$, and the CCL28 protein levels of the tumor and paired normal tissues were expressed as picograms per milligram $(\mathrm{pg} / \mathrm{mg})$. They were calculated from a standard curve of known values. All assays were carried out in triplicate and mean values were used for statistical calculations. Data are expressed as mean $\pm \mathrm{SD}$.

Statistical analysis. Data for the comparison of differences in CCL28 expression between normal and tumorous tissues were processed using SPSS (Statistical Package for the Social Sciences) version 10.0 for Windows (SPSS Inc., Chicago, IL). Differences in CCL28 levels in saliva between 

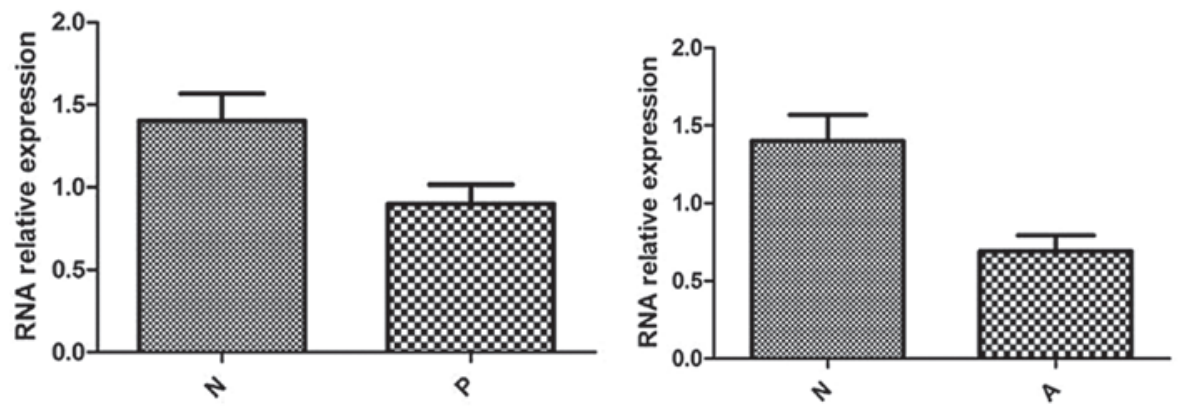

Figure 2. Relative expression of CCL28 mRNA in salivary gland tissues. mRNA was isolated, diluted to a uniform concentration, and used for RT-PCR. $\mathrm{N}$, normal salivary gland tissues; $\mathrm{P}$, pleomorphic adenomas; A, adenolymphomas.
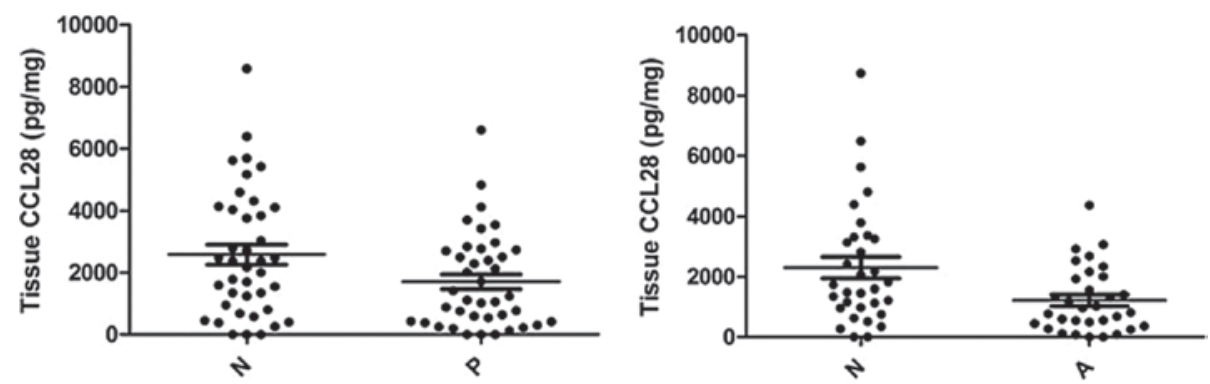

Figure 3. Distribution of the CCL28 protein expression level in human pleomorphic adenomas (P) and adenolymphomas (A) and matched normal tissues (N). The tissue level of CCL28 protein in salivary gland tumors had a significantly lower value versus paired normal tissue. Means are shown by horizontal bars.

patients and healthy volunteers were examined by the MannWhitney U test, and differences in CCL28 expression between tumor and normal paired tissues were examined by the Wilcoxon's signed rank test. P-values $<0.05$ were considered statistically significant.

\section{Results}

Immunohistochemical staining for CCL28. Immunohistochemistry was used to detect the localization of CCL28 expression in the sampled tissues. Fig. 1 shows immunohistochemical staining of CCL28 protein. Immunohistochemical reactivity for CCL28 was observed in the cytoplasm of acinar epithelial cells of the salivary glands. A heterogeneous staining of CCL28 protein was detected in the tumorous and the normal adjacent tissues. A strong intensity of immunostaining was observed in the normal adjacent salivary gland tissues (Fig. 1A and C), whereas pleomorphic adenoma and adenolymphoma tissues showed weak immunoactivity (Fig. 1B and D).

Regulated CCL28 mRNA expression in salivary gland tumors. We first used real-time PCR to examine the expression level of CCL28 by epithelium in the pleomorphic adenoma and adenolymphoma of human salivary glands. There was a significant difference between the levels of CCL28 mRNA in tumorous tissues and paired normal adjacent tissues. Among the 40 pleomorphic adenoma tissue pairs studied, 28 (70\%) tumors showed low expression of CCL28. A statistically significant difference was noted $(\mathrm{P}<0.05)$. It was also noted that 26 (81\%) adenolymphoma tissues exhibited low CCL28 mRNA expression $(\mathrm{P}<0.05)$. As a result of quantitative analysis, the relative expression of CCL28 in pleomorphic adenomas was $0.64(0.90 / 1.40)$-fold lower than the normal adjacent tissues, while expression in adenolymphomas was 0.49 (0.69/1.40)fold (Fig. 2).

Protein levels of CCL28 in salivary gland tumors. It is known that expression of cytokine and chemokine mRNA is not always well correlated with protein expression (10). Therefore, the CCL28 protein expression level was further determined by ELISA using protein-lysates of salivary gland tissues and matched normal tissues (Fig. 3). We found a significant difference $(\mathrm{P}=0.0027)$ in the levels of CCL28 protein in pleomorphic adenomas (median, $1672 \mathrm{pg} / \mathrm{mg}$ ) in comparison with paired normal tissue (median, $2576 \mathrm{pg} / \mathrm{mg}$ ). The levels of CCL28 protein in adenolymphoma (median, $1213 \mathrm{pg} / \mathrm{mg}$ ) were significantly lower $(\mathrm{P}=0.0003)$ than those in the paired normal tissue (median, $2386 \mathrm{pg} / \mathrm{mg}$ ).

Protein levels of CCL28 in saliva. Salivary levels of CCL28 were measured by ELISA in 45 healthy volunteers, 40 pleomorphic adenoma and 32 adenolymphoma patients. The mean saliva value for the healthy volunteers $(n=45)$ was $70.69 \mathrm{ng} / \mathrm{ml}$ with a standard deviation of $31.85 \mathrm{ng} / \mathrm{ml}$; the mean saliva CCL28 value of the pleomorphic adenoma patient was $36.91 \mathrm{ng} / \mathrm{ml}$ with a standard deviation of $26.05 \mathrm{ng} / \mathrm{ml}$; the mean saliva CCL28 level of the 32 adenolymphoma patients was $34.23 \mathrm{ng} / \mathrm{ml}$ with a standard deviation of $22.85 \mathrm{ng} / \mathrm{ml}$ (Table I). After statistical analysis, the level of saliva CCL28 protein in pleomorphic adenoma and adenolymphoma patients was significantly lower than that in the healthy volunteers $(\mathrm{P}<0.01)$. 
Table I. Saliva CCL28 levels.

\begin{tabular}{lcrr}
\hline $\begin{array}{l}\text { CCL28 concentration } \\
(\mathrm{C} ; \mathrm{ng} / \mathrm{ml})\end{array}$ & $\begin{array}{c}\text { Healthy volunteers } \\
(\mathrm{n}=45)\end{array}$ & $\begin{array}{c}\text { Pleomorphic adenoma patients } \\
(\mathrm{n}=40)\end{array}$ & $\begin{array}{c}\text { Adenolymphoma patients } \\
(\mathrm{n}=32)\end{array}$ \\
\hline $\mathrm{C} \leq 20$ & $3(6.7)$ & $10(25.0)$ & $8(25.0)$ \\
$20<\mathrm{C} \leq 40$ & $4(8.9)$ & $15(37.5)$ & $15(46.9)$ \\
$40<\mathrm{C} \leq 60$ & $8(17.8)$ & $8(20.0)$ & $5(15.6)$ \\
$60<\mathrm{C} \leq 80$ & $12(26.7)$ & $4(10.0)$ & $3(9.4)$ \\
$80<\mathrm{C} \leq 100$ & $8(17.8)$ & $2(2.5)$ & 0 \\
$100<\mathrm{C} \leq 120$ & $7(15.6)$ & $9(5.0)$ & 0 \\
$\mathrm{C}>120$ & $3(6.7)$ & 9 & 0 \\
\hline
\end{tabular}

The figures in the brackets are the percentages of healthy volunteers and aforementioned patient samples with the given concentrations of saliva CCL28. The mean saliva CCL28 levels $(\mathrm{ng} / \mathrm{ml}$, mean $\pm \mathrm{SD}$ ) were $70.69 \pm 31.85,36.91 \pm 26.05$ and $34.23 \pm 22.85$ in the healthy volunteers, pleomorphic adenoma and adenolymphoma patient groups, respectively.

\section{Discussion}

Chemokines are a large family of structurally related proteins, which possess multiple functions by interacting with their specific receptors to regulate the trafficking of leukocytes (11-13). CCL28 has been regarded as one of the major $\mathrm{CC}$ chemokines expressed in the epithelial cells of various mucosal tissues (6). Some previous studies suggest that alterations in CCL28 expression play a role in tumor pathogenesis. For example, CCL28 expression was found to be highly reduced or eliminated in breast tumors (14). In colon tumors, CCL28 is also significantly reduced compared with normal tissues (8). These data suggest that the reduction in the chemokine may be favorable to tumor growth. Contradictorily, research (15) has revealed that CCL28 plays a role in immune escape due to its recruitment of Treg. We conducted this study to clarify whether the chemokine CCL28 is involved in tumors of the salivary glands.

The results of the present study revealed that CCL28 mRNA in pleomorphic adenoma and adenolymphoma was significantly reduced compared with normal tissues. The results may be due to altered expression of related transcription factors in the generation of CCL28 mRNA synthesis. According to the ELISA results, the CCL28 protein level was significantly lower in tumor tissues in comparison with the paired normal tissues. We noted that the level of CCL28 was lower in pleomorphic adenoma compared with paired normal tissue $(\mathrm{P}=0.0047)$, and was significantly lower in adenolymphoma $(\mathrm{P}=0.0012)$. Meanwhile, the results of immunohistochemistry indicated that CCL28 was expressed in both tumors with weak staining compared to the strong immunoreactivity in normal salivary gland tissues.

The decreased expression of CCL28 in pleomorphic adenoma and adenolymphoma, shown in this study, may result in reduced populations of CCR10/CCR3 immune cells, most of which possess anti-tumor features, recruited to the salivary glands, thus enabling tumors to escape from immune surveillance. Based on our findings, we speculate that although CCL28 may recruit Treg cells bearing CCR10/CCR3, in the case of salivary glands the chemokine is perhaps mainly involved in recruiting immune competitive cells rather than regulatory cells. In this manner, increased CCL28 expression may terminate or reverse the occurrence and development of tumors in the salivary glands. Thus extended research is essential to confirm the types of immune cells responsible for the influence of CCL28 on tumor pathogenesis in salivary glands. This would facilitate further understanding of the underlying mechanisms of salivary gland carcinogenesis.

\section{Acknowledgements}

This study was supported by funding from the National Natural Science Foundation of China $(30171010,30371323)$ and the Natural Science Foundation of Shandong Province (Y2006c124).

\section{References}

1. Demasi AP, Furuse C, Soares AB, Altemani A and Araújo VC: Peroxiredoxin I, platelet-derived growth factor A, and plateletderived growth factor receptor alpha are overexpressed in carcinoma ex pleomorphic adenoma: association with malignant transformation. Hum Pathol 40: 390-397, 2009.

2. Faur A, Lazar E, Cornianu M, Dema A, Vidita CG and Galuscan A: Warthin tumor: a curious entity - case reports and review of literature. Rom J Morphol Embryol 50: 269-273, 2009.

3. Zlotnik A: Chemokines and cancer. Int J Cancer 119: 2026-2029, 2006.

4. Vandercappellen J, Van Damme J and Struyf S: The role of CXC chemokines and their receptors in cancer. Cancer Lett 267: 226-244, 2008.

5. Pan J, Kunkel EJ, Gosslar U, Lazarus N, Langdon P, Broadwell K, Vierra MA, Genovese MC, Butcher EC and Soler D: A novel chemokine ligand for CCR 10 and CCR 3 expressed by epithelial cells in mucosal tissues. J Immunol 165: 2943-2949, 2000.

6. Wang W, Soto H, Oldham ER, Buchanan ME, Homey B, Catron D, Jenkins N, Copeland NG, Gilbert DJ, Nguyen N, et al: Identification of a novel chemokine (CCL28), which binds CCR10 (GPR2). J Biol Chem 275: 22313-22323, 2000.

7. Hieshima K, Ohtani H, Shibano M, Izawa D, Nakayama T, Kawasaki Y, Shiba F, Shiota M, Katou F, Saito T and Yoshie O: CCL28 has dual roles in mucosal immunity as a chemokine with broad-spectrum antimicrobial activity. J Immunol 170: 1452-1461, 2003.

8. Dimberg J, Hugander A and Wagsater D: Protein expression of the chemokine, CCL28, in human colorectal cancer. Int J Oncol 28: 315-319, 2006.

9. Ogawa H, Iimura M, Eckmann L and Kagnoff MF: Regulated production of the chemokine CCL28 in human colon epithelium. Am J Physiol Gastrointest Liver Physiol 287: G1062-G1069, 2004. 
10. O'Gorman MT, Jatoi NA, Lane SJ and Mahon BP: IL-1beta and TNF-alpha induce increased expression of CCL28 by airway epithelial cells via an NFkappaB-dependent pathway. Cell Immunol 238: 87-96, 2005.

11. Zlotnik A and Yoshie O: Chemokines: a new classification system and their role in immunity. Immunity 12: 121-127, 2000.

12. Cheroutre H: IELs: enforcing law and order in the court of the intestinal epithelium. Immunol Rev 206: 114-131, 2005.

13. Ebert LA, Schaerli P and Moser B: Chemokine-mediated control of T cell traffic in lymphoid and peripheral tissues. Mol Immunol 42: 799-809, 2005.
14. Mickanin CS, Bhatia U and Labow M: Identification of a novel beta-chemokine, MEC, down-regulated in primary breast tumors. Int J Oncol 18: 939-944, 2001.

15. Facciabene A, Peng X, Hagemann IS, Balint K, Barchetti A, Wang LP, Gimotty PA, Gilks CB, Lal P, Zhang L and Coukos G: Tumour hypoxia promotes tolerance and angiogenesis via CCL28 and T(reg) cells. Nature 475: 226-230, 2011. 